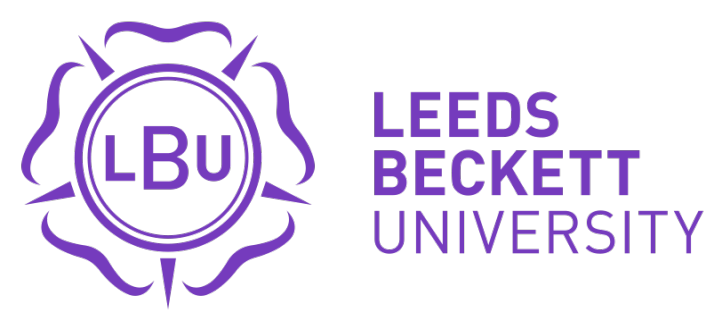

Citation:

Hudson, R and Wang, A and Rhodes, M and Zhang, S and Gregoriou, A (2020) Stock Liquidity and Return Distribution : Evidence from the London Stock Exchange. Finance Research Letters. ISSN 1544-6123 DOI: https://doi.org/10.1016/j.frl.2020.101539

Link to Leeds Beckett Repository record:

https://eprints.leedsbeckett.ac.uk/id/eprint/6688/

Document Version:

Article (Accepted Version)

Creative Commons: Attribution-Noncommercial-No Derivative Works 4.0

The aim of the Leeds Beckett Repository is to provide open access to our research, as required by funder policies and permitted by publishers and copyright law.

The Leeds Beckett repository holds a wide range of publications, each of which has been checked for copyright and the relevant embargo period has been applied by the Research Services team.

We operate on a standard take-down policy. If you are the author or publisher of an output and you would like it removed from the repository, please contact us and we will investigate on a case-by-case basis.

Each thesis in the repository has been cleared where necessary by the author for third party copyright. If you would like a thesis to be removed from the repository or believe there is an issue with copyright, please contact us on openaccess@leedsbeckett.ac.uk and we will investigate on a case-by-case basis. 


\title{
Stock Liquidity and Return Distribution: Evidence from the London Stock Exchange
}

\begin{abstract}
We investigate the relationship between liquidity and the distribution of returns, for all listed firms on the London Stock Exchange between 2002-2018. We find a strong relationship between the distribution of returns, as measured by skewness and kurtosis, and liquidity.
\end{abstract}

JEL codes: G12, G15, G33.

Key words: Skewness; Kurtosis; Liquidity; Amihud ratio; Bid-ask spread; Zero-return days. 


\section{Introduction}

There is substantial literature on the liquidity of stocks. Balasemi et al. (2015) describe liquidity as the buying and selling of a security with no considerable change in the price. Liquidity has proved to be difficult to observe, which has led to a number of liquidity measures being established in the academic literature including trading volume, bid-ask spread, zerotrading, zero-return days and various price impact models such as the Amihud ratio (Fong et al, 2017). A limited number of studies have linked liquidity to stock returns. Amihud et al. (2005) believe that liquidity predicts future returns. In addition, Baker and Stein (2004) show a positive relationship between liquidity and stock returns.

The overall distribution of stock returns is important for portfolio optimization, risk management and derivatives pricing. The shape of the return distributions can be parsimoniously captured by its skewness and kurtosis (its third and fourth moments). The skewness of the distribution captures the relative probability of positive and negative returns. The shape of the tails of the distribution are measured by kurtosis, which encapsulate the possibility of stock prices changing significantly (Ivanovski et al., 2015).

We are the first study to systematically associate liquidity with the distribution of returns, using five different liquidity measures over a 17-year time period. Amaya et al. (2015) discover that illiquidity is positively related with kurtosis, but they are more focused on return prediction. We provide evidence that skewness and kurtosis are an indicator of stock liquidity. We find that firms with a high degree of return asymmetry (larger absolute value of skewness) are highly illiquid, with a wider bid-ask spread, more zero-trading and zero-return days. The significant relationship between the distribution of returns and liquidity still exists, once we control for market capitalization, stock return volatility, trading volume and stock prices. 
The rest of this paper is organized as follows. Section 2 provides a brief review of the existing literature on liquidity measures. Section 3 discusses the data. Section 4 describes the methodology used to measure liquidity. The empirical analysis is reported in Section 5 and finally in Section 6 we present our conclusions.

\section{Literature review}

One of the standard measures of liquidity is the bid-ask spread, which is the difference between the lowest available quote to sell and the highest available quote to buy (Chordia et al., 2001). Liquidity can be encapsulated as the proportion of zero daily returns (ZeRet.). Lesmond et al. (1999) suggests that a zero-return day will occur when transaction costs are sufficiently high, compared with the value of the information held by informed traders or the requirement for liquidity by liquidity-motivated traders. Kang and Zhang (2014) propose a liquidity approximation based on zero volume days ( $\mathrm{ZeVol}$ ). Amihud (2002) develops a stock illiquidity ratio, denoted as the RtoV ratio. It examines the average ratio of the daily absolute return to the dollar trading volume on that trading day. The Amihud ratio, however, has some limitations. According to Florackis et al. (2011), the Amihud ratio is highly and negatively correlated with market capitalization and so exhibits an inherent size-related pattern. Therefore, Florackis et al. (2011) propose a new illiquidity ratio, which is comparable across firm sizes, defined as the average ratio of daily absolute stock return divided by its turnover ratio, denoted as the RtoTR ratio.

\section{Data}

We collect data from the universe of all UK firms, which were traded on the London Stock Exchange, over the period January 2002 to the end of December 2018 from Datastream. For each firm we obtain the company's daily closing price, bid price, ask price, trading volume (number of stocks traded), stock turnover (the average of shares outstanding during the period 
divided by total number of shares traded), and market capitalization (number of shares traded multiplied by the share price). Liquidity measures are computed as the average and the distribution of returns are calculated on a rolling one-month basis. We require that firms are not a financial company, utilities company or closed-end mutual fund. We also exclude preferred stocks. We only include companies that have complete data over the sample period. Our final dataset consists of 497 firms traded on the London Stock Exchange.

\section{Methodology}

\subsection{Skewness and kurtosis of returns}

Following Hutson et al (2008), the traditional test for the skewness of returns on a financial asset, $i$, is given in:

$$
\text { Skewness }=\frac{\frac{1}{N} \sum_{t=1}^{N}\left(R_{t-}^{i} \overline{R^{i}}\right)^{3}}{\left(\sigma^{i}\right)^{3}}
$$

Where $R_{t}^{i}$ is asset i's return at time t, $\sigma^{\mathrm{i}}$ is the standard deviation and $N$ is the number of observations in the population.

Following Ivanovski et al, (2015), we define the relative peakedness or flatness of a distribution compared with the normal distribution as:

$$
\text { Excess Kurtosis }=\frac{E\left[(x-\bar{x})^{4}\right]}{\sigma^{4}}-3
$$

\subsection{Bid-ask spread}

The bid-ask spread represents the difference between the lowest available quote to sell and the highest available quote to buy. The relative spread is defined as follows:

$$
\mathrm{RS}_{i, t}=\frac{\mathrm{A}_{i, t}-\mathrm{B}_{i, t}}{\left(\mathrm{~A}_{i, t}+\mathrm{B}_{i, t)} / 2\right.}
$$


Where $R S_{i, t}$ is the relative spread of stock $i$ at time period $t, A_{i, t}$ is the closing ask price of stock $i$ at time $t$ and $B_{i, t}$ is the closing bid price of stock $i$ at time period $t$.

\subsection{RtoV and RtoTR ratios}

The Amihud illiquidity ratio, or RtoV, is defined in the following equation:

$$
\mathrm{RtoV}_{\mathrm{i}}=\frac{1}{\mathrm{D}_{i}} \sum_{d=1}^{\mathrm{D}_{i}} \frac{\left|\mathrm{R}_{i, d}\right|}{\mathrm{V}_{i, d}}
$$

Where $\mid R_{i, d}$ land $V_{i, d}$ refers to the absolute return and monetary volume of stock $i$ on day $d$ respectively, and $D_{i}$ is the number of trading days for stock $i$.

The Florackis et al. (2011) price impact ratio, is defined as the average ratio of daily absolute stock return to its turnover ratio (RtoTR ratio):

$$
\operatorname{RtoTR}_{\mathrm{i}}=\frac{1}{\mathrm{D}_{i}} \sum_{d=1}^{\mathrm{D}_{i}} \frac{\left|\mathrm{R}_{i, d}\right|}{\mathrm{TR}_{i, d}}
$$

Where $T R_{i, d}$ refers to the turnover ratio of stock $i$ at day $d, D_{i}$ and $R_{i, d}$ are the same as previously defined in equation (4).

\subsection{Zero return days and zero trading days}

Lesmond et al. (1999) argue that a larger proportion of zero-return days should be observed for illiquid stocks. Their liquidity measure is defined as:

$$
\text { ZeRet }_{i, t}=\frac{\text { Numner of days with zero reutrns in a month }}{\text { Total number of trading days in a month }}
$$

If ZeRet is high, this means that stock $i$ has more zero return days in month $t$, which implies that the stock is more illiquid. A sibling measure of ZeRet is the proportion of zero-volume days, which is defined as follows: 


$$
\text { ZeVol. }=\frac{\text { No.of days with zero volumes in a month }}{\text { Total number of trading days in a month }}
$$

\subsection{Regression analysis}

Following Amaya et al. (2015), we test the relationship between various liquidity measures and the distribution of returns, once we account for a number of control variables by estimating the following pooled multivariate analysis:

$$
\begin{aligned}
& \text { Liq }_{i, t}=\beta_{0}+\beta_{1} \mid \text { Skew }_{i, t}++\beta_{2} \text { Price }_{i, t}+\beta_{3} \text { Size }_{i, t}+\beta_{4} \text { StdDev }_{i, t}+\beta_{5} \text { Vol }_{i, t}+\varepsilon_{i, \mathrm{t.t}} \\
& \text { Liq }_{i, t}=\beta_{0}+\beta_{1} \text { Kurt }_{i, t}+\beta_{2} \text { Price }_{i, t}+\beta_{3} \text { Size }_{i, t}+\beta_{4} \text { StdDev }_{i, t}+\beta_{5} \text { Vol }_{i, t}+\varepsilon_{i, \mathrm{i}} . \\
& \text { Liq }_{i, t}=\beta_{0}+{ }_{1} \mid \text { Skew }_{i, t} \mid+\beta_{2} \text { Kurt }_{i, t}+\beta_{3} \text { Price }_{i, t}+\beta_{4} \text { Size }_{i, t}+\beta_{5} \text { StdDev }_{i, t}+\beta_{6} \operatorname{Vol}_{i, t}+\varepsilon_{\mathrm{i}, \mathrm{t} .} .
\end{aligned}
$$

Where $\operatorname{Liq}_{i, t}$ is defined as the natural logarithm of the average daily five liquidity benchmarks, which are the bid-ask spread, RtoV and RtoTR ratios, zero-return days and zero-trading days, for stock $i$ at time $t$. Independent variables include the $\left|S k e w_{i, t}\right|$ and $K u r t_{i, t}$ which is the absolute value of skewness and kurtosis of stock $i$ at time $t$. Price $i, t$ is the natural logarithm of the daily closing price of stock $i$ at time $t$. Size $e_{i, t}$ captures the natural logarithm of the market capitalization of firm $i$ at time $t$. StdDevi,t is the daily return standard deviation which captures

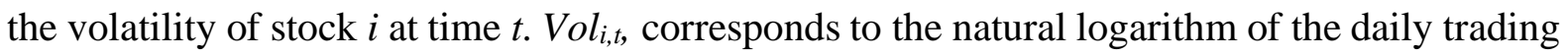
volume of stock $i$ at time $t$.

\section{Empirical results}

The results of the regressions of five liquidity measures on skewness and kurtosis are shown in Table 1. From Panel A we find that the coefficient on the variable $\mid$ skew $\mid$ is positive and highly significant for $R S$, RtoV and the RtoTR ratios, after controlling for the impact of stock prices, firm size, stock volatility and trading volume. For zero-return days and zero-trading days, the coefficients of $\mid$ skew $\mid$ are still positive at 0.145 and 0.327 respectively, although the coefficient of zero-return days is statistically insignificant. 
Panel B of Table 1 shows the results between kurtosis and liquidity. There is clear evidence that all the liquidity measures are affected by kurtosis at a significant level. All the coefficients of the liquidity measures are positive and significant at the $1 \%$ level except for ZeRet which, whilst still positive, is only significant at the $5 \%$ level. These results indicate that the distribution of returns has a significant economic and statistical impact on the illiquidity of stocks. The illiquid stocks tend to have higher return asymmetry, either positive or negative, and higher return kurtosis. In Panel C, we combine the $\mid$ skew $\mid$ and Kurtosis into one regression model. The results are similar to those in Panel A and Panel B in respect of both the magnitude and significance of the coefficients of the liquidity variables. For example, for $\mid$ skew $\mid$ the coefficients of $R S$, Rto $V$ and the RtoTR ratios are all positive and highly significant as in Panel A whereas the coefficients of zero-return days and zero-trading days are still positive but at a less significant level which again broadly corresponds to the results in Panel A. For Kurtosis, all the coefficients of the liquidity variables are positive and significant as in Panel B. The coefficients of Kurtosis are higher than $\mid$ skew $\mid$ across all of five liquidity model. In conclusions, as shown in Panels A and B, Skewness and Kurtosis are significant factors in explaining stock liquidity.

For the control variables, as expected, the stock price is negatively related to the illiquidity measure in both the skewness and kurtosis models. Size has a statistically significant effect on RtoV with coefficient values of -0.689 in the skewness model, -0.573 in the kurtosis model and -0.494 in the combination model. By comparison, the coefficient estimate for firm size is positive but statistically insignificant for the RtoTR ratio. Our results provide evidence confirming the prior finding in the literature that the Rto $V$ ratio contains firm size bias, whereas the RtoTR has no statistically significant relationship with firm size. 
[INSERT TABLE 1 HERE]

\section{Conclusion}

We examine the empirical relationship between the distribution of returns and stock liquidity. Controlling for market capitalization, stock return volatility, trading volume and stock price at firm level, we find evidence that stocks with a high degree of asymmetry are less liquid. This is because they exhibit a larger bid-ask spread, more zero-trading and zero-return days. Even though the skewness results are insignificant for the zero-return days model, the Kurtosis results are statistically significant in all of the five liquidity measures. A stock's kurtosis also negatively affects the liquidity level. Further research might consider the implications of our findings for areas such as portfolio theory, asset pricing, risk management and derivatives pricing. 


\section{References}

Amaya, D., Christoffersen, P., Jacobs, K. and Vasquez, A., (2015), “Does realized skewness predict the cross-section of equity returns?". Journal of Financial Economics, Vol.118(1), pp.135-167.

Amihud, Y. (2002), "Illiquidity and stock returns: Cross-section and time-series effects." Journal of Financial Markets, Vol.5, pp.31-56.

Amihud, Y., Mendelson, H., and Pedersen, H., (2005), "Liquidity and asset prices", Foundations and Trends in Finance, Vol.1(4), pp. 269-364.

Baker, M., and Stein, J.C., (2004), "Market liquidity as a sentiment indicator", Journal of Financial Markets, Vol.7, pp.271-299.

Balasemi, N., Veiseh, S.M., and Malgharani, A.M., (2015), "Relationship between liquidity and stock returns considering company's life cycle: The case study of Tehran stock exchange listed companies”. Walia Journal. Vol. 31 (S4), pp.85-91.

Chordia, T., Roll, R., and Subrahmanyam, A., (2001), "Market liquidity and trading activity”, Journal of Finance, Vol.56, pp. 501-530. 
Florackis,C., Gregoriou, A., and Kostakis,A., (2011), “Trading frequency and asset pricing on the London Stock Exchange: Evidence firm a new price impact ratio”, Journal of Banking \& Finance, Vol.35(12), pp.3335-3350.

Fong, K.Y.L., Holden.C.W., and Trzcinka, A., (2017), "What are the best liquidity proxies for global research?", Review of Finance, Vol.21(4), pp.1355-1401.

Hutson, E., Kearney, C., and Lynch, M., (2008), "Volume and skewness in international equity markets", Journal of Banking and Finance, Vol.32, pp.1255-1268.

Ivanovski, Z., Stojanovski, T. and Narasanov, Z., 2015. Volatility and kurtosis of daily stock returns at MSE. UTMS Journal of Economics, 6(2), pp.209-221.

Lesmond, D.A., Ogden, J.P., and Trzcinka,C.A., (1999),“A new estimate of transaction costs”, Review of Financial Studies, Vol.12, pp.1113-1141. 


\section{Table 1 Regression analysis between liquidity and return distribution}

A log-linear pooled time series cross-sectional multivariate analysis of skewness, kurtosis and various liquidity measures is estimated as follows:

$$
\begin{aligned}
& \text { Liq }_{i, t}=\beta_{0}+\beta_{1} \mid \text { Skew }_{i, t} \mid+\beta_{2} \text { Price }_{i, t}+\beta_{3} \text { Size }_{i, t}+\beta_{4} \text { StdDev }_{i, t}+\beta_{5} \operatorname{Vol}_{i, t}+\varepsilon_{i, t .} \\
& \text { Liq }_{i, t}=\beta_{0}+\beta_{1} \text { Kurt }_{i, t}+\beta_{2} \text { Price }_{i, t}+\beta_{3} \text { Size }_{i, t}+\beta_{4} \text { StdDev }_{i, t}+\beta_{5} \operatorname{Vol}_{i, t}+\varepsilon_{i, t .} \\
& \text { Liq }_{i, t}=\beta_{0}+{ }_{1} \mid \text { Skew }_{i, t} \mid+\beta_{2} \text { Kurt }_{i, t}+\beta_{3} \text { Price }_{i, t}+\beta_{4} \text { Size }_{i, t}+\beta_{5} \text {SStdDev }_{i, t}+\beta_{6} \operatorname{Vol}_{i, t}+\varepsilon_{i, \mathrm{it}}
\end{aligned}
$$

Regression variables are defined as the following: $L i q_{i, t}$ represents the natural logarithm of the average daily five liquidity benchmarks, Relative spreads, RtoV ratio, RtoTR ratio, ZeRet. and ZeVol., for stock $i$ in time period $t$. Independent variables include the absolute value of skewness, $|S k e w|$, of stock $i$ at time $t$. Kurtosis is the return kurtosis of stock $i$ at time $t$. Price $e_{i, t}$, is the natural logarithm of the stock $i$ 's daily closing price. Size $e_{i, t}$ captures the natural logarithm of the market capitalization of firm $i$ at time $t$. StdDevi,t represents the daily return volatility in time period t. $V_{o l} l_{i, t}$, is the natural logarithm of the daily trading volume of stock $i$ at time $t$. Two tailed tests of

\begin{tabular}{|c|c|c|c|c|c|c|c|c|c|c|}
\hline & \multicolumn{2}{|c|}{$\mathrm{RS}$} & \multicolumn{2}{|c|}{ RtoV } & \multicolumn{2}{|c|}{ RtoTR } & \multicolumn{2}{|c|}{ ZeRet } & \multicolumn{2}{|c|}{ ZeVol } \\
\hline & Coef & T-sat. & Coef. & T-stat. & Coef. & T-stat & Coef. & T-stat & Coef. & T-stat. \\
\hline C. & 1.256 & $5.99^{* * *}$ & 3.408 & $7.24^{* * * *}$ & 3.555 & $7.80^{* * * *}$ & 1.574 & $5.37^{* * * *}$ & 1.648 & $5.94^{* * *}$ \\
\hline |Skew| & 0.649 & $4.81^{* * * *}$ & 0.617 & $5.65^{* * * *}$ & 0.442 & $3.91^{* * * *}$ & 0.145 & 1.23 & 0.327 & $2.55^{* *}$ \\
\hline Price & -0.231 & $-2.79^{* *}$ & 0.006 & 1.09 & 0.023 & 1.42 & -0.731 & $-4.87^{* * *}$ & -0.736 & $-4.64^{* * *}$ \\
\hline Size & -0.673 & $-5.06^{* * * *}$ & -0.689 & $-5.94^{* * * *}$ & 0.018 & 1.05 & -0.696 & $-5.91^{* * * *}$ & -0.579 & $-5.08^{* * *}$ \\
\hline StdDev & 0.477 & $3.83^{* * * *}$ & 0.160 & $1.51^{*}$ & 0.134 & $1.49^{*}$ & -0.639 & $-3.08^{* * * *}$ & -0.601 & $-2.86^{* *}$ \\
\hline Vol. & -0.416 & $-3.28^{* *}$ & -0.714 & $-6.33^{* * * *}$ & -0.029 & $1.52^{*}$ & -0.448 & $-4.23^{* * *}$ & -0.775 & $-5.03^{* * *}$ \\
\hline
\end{tabular}
significance are reported as follows, ${ }^{* * *}$ significance at $1 \%,{ }^{* *}$ significance at $5 \%$ and ${ }^{*}$ significance at $10 \%$.

Panel A: Skewness

\begin{tabular}{|c|c|c|c|c|c|c|c|c|c|c|}
\hline & \multicolumn{2}{|c|}{$\mathrm{RS}$} & \multicolumn{2}{|c|}{ RtoV } & \multicolumn{2}{|c|}{ RtoTR } & \multicolumn{2}{|c|}{ ZeRet } & \multicolumn{2}{|c|}{ ZeVol } \\
\hline & Coef. & T-sat. & Coef. & T-stat. & Coef. & T-stat. & Coef. & T-stat. & Coef. & T-stat. \\
\hline $\mathbf{C}$ & 2.334 & $7.05^{* * * *}$ & 1.968 & $6.26^{* * * *}$ & 1.304 & $5.50^{* * *}$ & 1.246 & $5.02^{* * * *}$ & 1.066 & $5.35^{* * * *}$ \\
\hline Kurtosis & 0.431 & $3.26^{* *}$ & 0.632 & $4.25^{* * * *}$ & 0.648 & $6.06^{* * *}$ & 0.237 & $2.85^{* *}$ & 0.549 & $3.86^{* * * *}$ \\
\hline Price & -0.146 & $-2.10^{*}$ & 0.000 & 0.73 & 0.014 & 1.37 & -0.698 & $-3.01^{* *}$ & -0.711 & $-3.49^{* * * *}$ \\
\hline Size & -0.318 & $-2.93^{* *}$ & -0.573 & $-4.89^{* * * *}$ & -0.001 & -0.96 & -0.445 & $-2.96^{* *}$ & -0.524 & $-3.11^{* *}$ \\
\hline StdDev & 0.561 & $3.14^{* *}$ & 0.124 & 1.23 & 0.215 & $1.73^{*}$ & -0.666 & $-2.04^{*}$ & -0.428 & $-2.86^{* *}$ \\
\hline Vol. & -0.438 & $-3.07^{* *}$ & -0.697 & $-5.48^{* * * *}$ & -0.009 & 0.99 & -0.614 & $-3.45^{* * *}$ & -0.713 & $-4.68^{* * * *}$ \\
\hline \multicolumn{11}{|c|}{ Panel C: Skewness and Kurtosis } \\
\hline & \multicolumn{2}{|c|}{$\mathrm{RS}$} & \multicolumn{2}{|c|}{ RtoV } & \multicolumn{2}{|c|}{ RtoTR } & \multicolumn{2}{|c|}{ ZeRet } & \multicolumn{2}{|c|}{$\mathrm{ZeVol}$} \\
\hline & Coef & T-sat. & Coef. & T-stat. & Coef. & T-stat & Coef. & T-stat & Coef. & T-stat. \\
\hline C. & 1.314 & $6.08^{* * *}$ & 1.076 & $7.44^{* * *}$ & 2.195 & $7.92^{* * *}$ & 1.038 & $5.24^{* * *}$ & 2.314 & $7.31^{* * *}$ \\
\hline |Skew| & 0.568 & $4.24^{* * * *}$ & 0.413 & $3.56^{* * * *}$ & 0.334 & $2.97^{* *}$ & 0.106 & 1.41 & 0.145 & $1.94^{*}$ \\
\hline Kurtosis & 0.669 & $5.99^{* * *}$ & 0.536 & $4.27^{* * * *}$ & 0.518 & $4.02^{* * *}$ & 0.394 & $2.95^{* *}$ & 0.447 & $3.78^{* * *}$ \\
\hline Price & -0.029 & -1.03 & 0.000 & 0.44 & -0.000 & -0.56 & -0.435 & $-3.17^{* *}$ & -0.537 & $-5.09^{* * *}$ \\
\hline Size & -0.401 & $-3.81^{\text {*** }}$ & -0.494 & $-3.98^{* * *}$ & -0.000 & -0.73 & -0.548 & $-4.64^{* * *}$ & -0.694 & $-6.13^{* * *}$ \\
\hline StdDev & 0.308 & $2.46^{* *}$ & 0.140 & $1.86^{*}$ & 0.236 & $2.08^{*}$ & -0.416 & $-3.06^{* *}$ & -0.608 & $-5.84^{* * *}$ \\
\hline Vol. & -0.152 & $-1.99^{*}$ & -0.791 & $-5.95^{* * *}$ & -0.014 & -1.13 & -0.503 & $-4.29^{* * *}$ & -0.419 & $-3.37^{* * *}$ \\
\hline
\end{tabular}

Panel B: Kurtosis 
